\title{
Cultura, Mídia e Direitos humanos
}

\author{
Cultura, medios de comunicación y los derechos humanos
}

Culture, Media and Human Rights

Prof. Dra. Janaína Bilate ${ }^{1}$
Fernanda Conde $^{2}$

Lais Olimpio

Lucas Pinheiro e Marco Antonio Silva

\begin{abstract}
Resumo
Este trabalho é o resultado do Projeto de Pesquisa e Extensão Cultura, Mídia e Direitos Humanos, que visa contribuir com o estímulo de ações educativas na temática direitos humanos, bem como assessorar e estimular ações políticas coletivas no âmbito da pressão pelo acesso a direitos. Intentou-se descortinar sobre e desenvolver processos de potencialização da consciência crítica e emancipatórios, visando o acesso a direitos e a educação em direitos humanos através de estímulos culturais.
\end{abstract}

Palavras-chave: Cultura; Direitos Humanos; Educação; Formação Política; Mídia.

\section{Resumen}

Este trabajo es el resultado de la investigación y la extensión del Proyecto Cultura, Medios de Comunicación y Derechos Humanos, cuyo objetivo es contribuir a la estimulación de las actividades educativas sobre el tema de los derechos humanos y el asesoramiento y promoción de las acciones políticas colectivas bajo presión por el acceso a los derechos. Se lleva a cabo los procesos de empoderamiento descubrir y desarrollar la conciencia crítica y emancipadora, que pretenda ingresar a la educación en derechos humanos y derechos a través de estímulos culturales.

Palabras claves: Cultura; Derechos Human; Educación; Formación Política; Medios de Comunicación.

\begin{abstract}
This extension project aims to contribute to the stimulation of educational activities in the thematic human rights, as well as advisory and stimulate collective political actions under pressure for access to rights. The shares are held in the Caju neighborhood which has the lowest HDI in Rio de Janeiro, territory terminating various rights violations, from violence of all kinds to the quality of particulate air, which directly involves breathing its residents.
\end{abstract}

Key-Words: Cultura; Human Rigths; Education; Political Education, Social Media.

\footnotetext{
${ }^{1}$ Doutora em Serviço Social; Escola de Serviço Social - UNIRIO; Rio de Janeiro, Rio de Janeiro, Brasil; janainabilate@ hotmail.com. Trabalho apresentado no I Seminário Latino-Americano de Estudos em Cultura SEMLACult, Foz do Iguaçu/PR, Brasil, 2017.

${ }^{2}$ Graduandos em Serviço Social; Escola de Serviço Social - UNIRIO; Bolsistas de Extensão e Integrante do projeto; Rio de Janeiro, Rio de Janeiro, Brasil; fernandacond@gmail.com; laís.102@hotmail.com; lucaseumeimporto@gmail.com; marcosilva.nave@gmail.com. Trabalho apresentado no I Seminário LatinoAmericano de Estudos em Cultura - SEMLACult, Foz do Iguaçu/PR, Brasil, 2017.
} 


\title{
1. Introdução
}

O presente Projeto de Extensão “Cultura, Mídia e Direitos Humanos: potencialização da consciência crítica e desenvolvimento de processos emancipatórios" visa fortalecer os saberes populares e a democratização das informações objetivando, por meio da educação em direitos humanos e da formação política, contribuir para a melhoria da qualidade de vida dos sujeitos envolvidos, bem como aclarar sobre e como acessar direitos.

Neste sentido, as possibilidades de construção de "um outro mundo factível" perpassa pela aproximação ao gênero humano e suas potencialidades emancipatórias proporcionadas pela crítica à reprodução automática da realidade e com reflexão acerca da materialidade da vida cotidiana. Desta forma, busca-se estimular à solidariedade, o respeito às diferenças e a promoção da concepção de alteridade, a liberdade, a justiça social, visando à formação do sujeito "consciente" de direitos, auto-confiante e auto-construtor de sua trajetória de vida, à luz da Política Nacional em Direitos Humanos, Eixo orientador V:

\begin{abstract}
A educação em Direitos Humanos, como canal estratégico capaz de produzir uma sociedade igualitária, extrapola o direito à educação permanente e de qualidade. Trata-se de mecanismo que articula, entre outros elementos: a) a apreensão de conhecimentos historicamente construídos sobre Direitos Humanos e a sua relação com os contextos internacional, nacional, regional e local; b) a afirmação de valores, atitudes e práticas sociais que expressem a cultura dos Direitos Humanos em todos os espaços da sociedade; c) a formação de consciência cidadã capaz de se fazer presente nos níveis cognitivo, social, ético e político; d) o desenvolvimento de processos metodológicos participativos e de construção coletiva, utilizando linguagens e materiais didáticos contextualizados; e) o fortalecimento de políticas que gerem ações e instrumentos em favor da promoção, da proteção e da defesa dos Direitos Humanos, bem como da reparação das violações. (p.150)
\end{abstract}

Desta forma, em nossa direção teórico-metodológica, dentre as inúmeras capacidades inerentes às artes e à cultura, de forma ampliada, visamos utilizar neste projeto de extensão a noção de que as artes e a cultura podem alargar horizontes no que tange à compreensão da vida humana em sociedade, contribuindo para a (re)produção de novos valores sociais, orientados pelos parâmetros supracitados. Neste sentido, pretende-se contribuir com a fruição da educação em direitos humanos à luz da PNDH-3.

\section{Trajetória do Projeto}

Projeto de Extensão, então intitulado Cultura, Mídia e Direitos Humanos, com o objetivo inicial de buscar fortalecer os saberes populares e a democratização das informações, 
por meio da educação em direitos humanos e da formação política, até então atuante na Comunidade do Santa Marta, Botafogo, RJ, passa a aturar no Bairro do Caju em fevereiro de 2014. Cabe mencionar que este projeto é parte integrante do Programa Centro de Referência em Direitos Humanos (CRDH), um programa de extensão de prática jurídica em assessoria jurídica popular, educação em direitos humanos e formação política das Escolas de Ciências Jurídicas, Ciência Política e Serviço Social da Universidade Federal do Estado do Rio de Janeiro (UNIRIO).

No decorrer das atividades, fomos percebendo sobre a demanda considerável por assessoria aos movimentos sociais já organizados no território ${ }^{3}$ e, com isto, nos instigou a pensar na construção de uma pesquisa que trouxesse claramente a relevância da dimensão investigativa no âmbito do trabalho profissional.

Vale ressaltar que o projeto de extensão, e em seu bojo o de pesquisa, busca reafirmar a concepção de acesso a direitos na esfera pública estatal, buscando a superação cultural da noção de privilégio em detrimento de direitos. Igualmente, não é objetivo do projeto fornecer serviços sociais de responsabilidade legal e ético-política de equipamentos de política social.

Desta forma, nossa proposta de assessoria aos movimentos sociais e o apoio aos projetos comunitários de capacitação de agentes públicos e populares pela educação popular em Direitos Humanos, especialmente nos temas da participação política democrática, não intenta um retorno à perspectiva da modernização conservadora (NETO, 1991).

O Bairro do Caju, onde se realiza o projeto, fica na Zona Portuária do Rio de Janeiro, no entanto ficando de fora do alcance do Projeto Porto Maravilha. O Caju é uma das áreas com menor IDH da Cidade do Rio de Janeiro, com IDH de 0,775, o 24º da Área Programática 1.0, alto nível de abandono, exploração violenta da força de trabalho, agressão ambiental. No Bairro se materializam vários níveis violações de direitos, desde o direito a respirar, até o de se locomover, tendo em vista o excesso de carretas das empresas que ali exploram o processo de importação/exportação do porto, ou que produzem matéria prima para empreiteiras, tais como as usinas de asfalto e cimento.

\footnotetext{
${ }^{3}$ No Bairro do Caju existem em torno de 9 comunidades, fragmentadas, que não articulam entre si enquanto bairro. Todas enfrentam as mesmas expressões da questão social, com maior ou menor intensidade, e não percebem a necessidade da unificação das lutas, tendo em vista a similaridade das demandas. Um exemplo, os equipamentos de polícia social, principalmente algumas creches e escolas, situam-se em áreas de risco ambiental por situarem-se no entorno de fábricas de cimento e asfalto.
} 
Embora haja no território uma articulação político-organizativa apartidária, a REDE Socioassintencial do Caju, que agrega os mais diversos sujeitos, desde os moradores (base e lideranças), trabalhadores da região e empresariado, os moradores não conseguem pressionar o governo senão em época de eleição face às ações personalistas eleitoreiras que se instaura na região, legitimando as particularidades da formação do Estado brasileiro em seu fisiologismo (CARVALHO, 2002).

Aqui não é Porto Maravilha: para o Caju absolutamente nada. As pessoas aqui simplesmente não existem. É necessário trazer o Caju para discussão. Trazer visibilidade ao CAJU. Discutir sobre ciências ambientais, os Parques sanitários. Começar a discutir que saia do interesse individual e và para um interesse mais comum. São cerca de 30 mil pessoas nessa condição.

Assistente Social, por ocasião da reunião de articulação entre o projeto CMDH e a Rede Socioassistencial do Caju

Uma outra questão que nos instiga ao observarmos concretamente o Bairro do Caju, que por certo não é fato exclusivo da região, é que o território é pouco beneficiado por projetos e programas de governo, e em anos eleitorais, a quantidade de políticos articulados a algumas lideranças comunitárias, sejam elas de associações de moradores, tráfico ou milícia, na defesa de um populismo histórico, promete criar projetos e programas que beneficiem a população já bastante violada em uma gama de direitos. E de certo, é um desafio ao projeto, visto que a população já aprendeu a conviver com os projetos eleitoreiros e se organizam de acordo com seus interesses.

\section{Nossa orientação teórica}

De modo a desenvolver estas ações, defendemos que a cultura é uma mediação fundamental para a (re)produção social, e pode constituir um espaço de criação de alternativas no âmbito da consciência crítica. Na atualidade do modo de produção capitalista, o campo da cultura também pode consistir em uma alternativa estratégica das classes subalternas na busca pela legitimação dos direitos garantidos pela Constituição de 1988 e sua consequente precarização, face às políticas de retração estatal na provisão de direitos vigente no Brasil, mormente desde a segunda metade da década de 90.

Compreendemos que as ações culturais que contribuam para a potencialização da consciência crítica e de ações políticas coletivas, podem, em alguma medida, estimular um projeto alternativo às vigentes relações estado-sociedade, objetivando a reprodução de uma nova hegemonia, ou seja, de uma nova direção intelectual e moral. 
Historicamente, as ações educativas através da arte têm sido desenvolvidas por inúmeras formas de expressão: teatro, cinema, rádio, literatura, artes plásticas, música, circo, dança. Este processo se realiza visto que as manifestações artísticas constituem um campo fértil para reflexões acerca dos valores culturais e ideológicos nos termos gramscianos ${ }^{4}$ : cultura como o modo de viver, de agir e reagir, de pensar, de vivenciar subjetiva e objetivamente a realidade, de sujeitos sociais inseridos em um dado modo de produção, historicamente situados.

O ser social tem como objetivação primária o trabalho ${ }^{5}$, mas a práxis -compreendida como o conjunto de objetivações que ocorrem fundamentalmente no trabalho e em outras esferas, tais como religião, artes, filosofia, política, entre outros - não se restringe àquela objetivação primária: é mais ampla, abrangendo as diferentes manifestações do ser social.

A categoria de práxis permite apreender a riqueza do ser social desenvolvido: verifica-se, na e pela práxis, como, para além das suas objetivações primárias, constituídas pelo trabalho, o ser social se projeta e se realiza nas objetivações materiais e ideais da ciência, da filosofia, da arte, construindo um mundo de produtos, obras e valores - um mundo social, humano enfim, em que a espécie humana se converte inteiramente em gênero humano. Na sua amplitude, a categoria de práxis revela o homem como ser criativo e autoprodutivo: ser da práxis, o homem produto e criação da sua auto-atividade, ele é o que (se) fez e (se) faz (NETTO \& BRAZ, 2006:44).

Ao perpassarmos os tempos históricos, vemos que a organização da cultura de determinado povo é um dos vetores componentes do processo de reprodução social daquele. A cultura é determinante e determinada por vários fatores que, historicamente situados e processualmente construídos, caracterizam a identidade ${ }^{6}$ dos mais diversos grupos sociais.

\footnotetext{
${ }^{4}$ Antonio Gramsci, autor Italiano, que desenvolveu suas reflexões sobre educação e cultura tendo como base de reflexão a tradição histórico-crítica de análise. Para Gramsci, a luta pela hegemonia não prescinde das questões econômicas, mas a esfera ideológica e cultural são solos férteis para este processo: "O desenvolvimento de uma consciência crítica em relação à concepção hegemônica vigente e de uma ação política articulada e de propostas superiores de sociedade como pressuposto subjetivo e objetivo para a formação de um processo de catarse na direção da construção de uma nova hegemonia das classes subalternas implica, necessariamente, na transformação da sua bagagem ideocultural. Isso porque Gramsci recolhe de Marx a idéia de que os homens fazem a sua história, mas não a fazem nas condições que escolheram, podendo suas ações e atitudes muitas vezes serem determinadas por aquilo que lhes escapa e que lhes é estranho". (DURIGUETO, 2007: 62)

${ }^{5}$ Categoria da Economia Política, fundante do ser social, visto que, em sua relação com a natureza, por meio de instrumentos que mediam esta relação, a transformam, criando valor.

${ }^{6}$ Identidade como conjunto simbólico de significações que diferenciam os grupos sociais, fruto de um processo consciente de vinculação, de pertencimento, baseada em oposições simbólicas. A noção de identidade pode ser utilizada como estratégia política de luta por direitos. Cabe mencionar que a identidade cultural é um componente da identidade social - conjunto de vinculação de indivíduos. Dentre os estudiosos sobre o tema, destacamos Stuart Hall, que em Identidades culturais na pós-modernidade (DP\&A Editora, 1999), faz uma análise da identidade do sujeito social sob uma perspectiva historicizada.
} 
Como nos aponta Barroco, decerto que as categorias econômicas possuem uma função primária no modo de produção capitalista, pois nenhuma outra "esfera da vida social pode se reproduzir sem responder às suas determinações" (BARROCO, 2005:25). No entanto, a esfera da cultura encerra um componente importante da reprodução social, que a partir do trabalho pois é seu produto -, fundam a história: "O trabalho e seu produto, a cultura, fundam a história, autoconstrução dos próprios homens, em sua relação recíproca com a natureza" (Idem, 28).

Coaduna-se com a afirmativa de que é na esfera cultural, tendo as expressões de arte como uma de suas mediações, bem como a Escola, a Imprensa e a Igreja, que se gesta a possibilidade de uma classe dominada criar e reproduzir uma concepção de mundo articulada aos seus interesses de classe e difundi-la, tornando-se dirigente. Na perspectiva gramsciana, é neste processo, primeiro tornando-se dirigente, que se constrói a hegemonia de uma determinada classe.

Orientados por estas perspectivas é que entendemos que a ampliação de ações de educação em Direitos Humanos e Formação Política para a emancipação dos sujeitos pode ser desenvolvida por meio de ações pedagógico-culturais, tendo como cenário a preocupação recente, em termos de história do Brasil, com a questão sobre os Direitos Humanos.

No Brasil, vive-se um período particularmente fértil nesse sentido na década de 60 , quando inúmeras atividades desenvolvidas no campo da esquerda, no âmbito da música, da literatura, do cinema e do teatro voltam-se à crítica social, à cultura popular e ao engajamento político, a exemplo das ações dos Centros Populares de Cultura - CPC, do Teatro de Arena, do Teatro Opinião, do Teatro União e Olho Vivo, de grupos populares, para citar alguns, e do engajamento de alguns intelectuais brasileiros, que não respondiam à ideologia do favor nem favoreciam o "intimismo à sombra do poder"?

\footnotetext{
${ }^{7}$ Ao analisar a emergência do intelectual do século XIX, Coutinho na obra citada anteriormente registra que esta expressão é de Thomas Mann e usada por Lukács: "O intelectual cooptado não tem necessariamente de ser um apologeta direto do regime social que o mantém e do Estado ao qual está ligado. Ele pode, em sua criação cultural ou artística, cultivar sua própria intimidade, ou seja, de dar expressão a ideologias ou estilos estéticos que lhe pareçam os mais adequados à sua subjetividade criadora. Mas o fato é que a própria situação de isolamento em face dos problemas do povo-nação, a "torre de marfim" voluntária ou involuntária em que é posto pela situação de cooptação (e pela ausência da sociedade civil), faz com que essa cultura elaborada pelos intelectuais "cooptados" evite pôr em discussão as relações sociais de poder vigentes, com as quais estão direta ou indiretamente comprometidos". (2000: 24).
} 
O cenário político desta movimentação pré-golpe de 64 fora emoldurado pela presidência de João Goulart e suas Reformas de Base $^{8}$. As condições objetivas para a ampliação da participação das massas nas decisões estatais e para uma possível redistribuição da riqueza de forma mais eqüitativa - em um primeiro momento sem questionar o modo de produção capitalista (NETTO, 1991) - estimularam as crescentes manifestações, principalmente no campo da cultura - arte, jornalismo, educação.

Em termos gramscianos, em contraposição à hegemonia ${ }^{9}$ dominante, as classes subalternas devem-se organizar visando à elaboração e construção de uma cultura contrahegemônica como a principal estratégia destas, subalternizadas historicamente. Para o autor em tela, hegemonia não resta tão somente na esfera da política, como também na da economia, na da cultura, na da moral, na da ética, na concepção de mundo. E neste sentido, as manifestações artístico-culturais podem ser consideradas espaços de reflexão crítica e de criação teórico-prática de uma concepção de mundo diversa da dominante, suscitada pelo questionamento dos valores dominantes.

Trata-se, portanto, de elaborar uma concepção nova, que parta do senso comum, não para se manter presa ao senso comum, mas para criticá-lo, depurá-lo, unificá-lo e elevá-lo àquilo que Gramsci chama de bom senso, que é pra ele a visão crítica do mundo. Deve-se observar que, quando se fala da concepção cultural mais elevada como "bom senso", é que se tem uma visão não aristocrática da cultura. É que se está orientando por uma profunda preocupação com o vínculo entre a cultura e as grandes massas (e o modo de sentir dessas massas). (GRUPPI, 2000:69).

Diante deste quadro, um dos grandes desafios atuais dos trabalhadores, depois dos anos de chumbo, os avanços da Carta de 1988 e os avanços do neoliberalismo, é a reconquista destes direitos historicamente alcançados pela luta da classe trabalhadora ${ }^{10}$.

\footnotetext{
${ }^{8}$ Reformas estruturais propostas pela equipe do Presidente João Goulart (1961-1964), as quais propunham reformulações nos setores de educação, economia (fiscal), política e agrário. As Reformas de Base se tornaram a bandeira do governo João Goulart e consistia em uma proposta direcionada às classes subalternas.

${ }^{9} \mathrm{O}$ conceito de hegemonia em Gramsci é objeto de estudo de grande importância, dentre eles destacamos o de GRUPPI, Luciano. O Conceito de Hegemonia em Gramsci. 4a edição. Rio de Janeiro: Edições Graal, 2000. Hegemonia consiste em um complexo sistema de relações e mediações configurando a capacidade de direção de determinado grupo social - seus valores, sua política, sua base econômica, sua direção intelectual e moral. "(...) o conceito de hegemonia é apresentado por Gramsci em toda sua amplitude, isto é, como algo que opera não apenas sobre a estrutura econômica e sobre a organização política da sociedade, mas também sobre o modo de pensar, sobre as orientações ideológicas e inclusive sobre o modo de conhecer. (...) Para Gramsci, a realização de um aparato hegemônico - enquanto cria um novo terreno ideológico determina uma reforma das consciências, novos métodos de conhecimento, sendo assim, um evento filosófico" (GRUPPI, 2000: 3; 4).

10 "Todas as transformações implementadas pelo capital têm como objetivo reverter a queda da taxa de lucro e criar condições renovadas para a exploração da força de trabalho. Compreende-se, pois, que o ônus de todas elas recaiam fortemente sobre os trabalhadores - da redução salarial (um exemplo: nos Estados Unidos, entre 1973 e 1992, o preço da hora de trabalho daqueles envolvidos diretamente na produção caiu de US\$10,37 para US\$
} 
Neste processo, direcionados por aportes gramscianos, a disputa política das classes subalternas pode ter o campo da cultura como importante estratégia na educação em direitos humanos e para formação política. Visando à cultura à luz das reflexões de Antonio Gramsci, vislumbramos ser este um dos espaços de possibilidade de formular propostas e ações que visem à construção de uma consciência crítica e de uma vivência política, que objetivem a construção da hegemonia destas classes. Para tal, Gramsci nos aponta os efeitos da "catarse", ou seja, a passagem do momento meramente econômico-coporativo de uma classe para o momento ético-politico, de dimensões universais: "Segundo Gramsci, se uma classe social não é capaz de efetuar esta "catarse", não pode se tornar uma classe nacional, ou seja, não pode representar os interesses universais de um bloco histórico e, por conseguinte, não pode conquistar a hegemonia na sociedade" (COUTINHO, 2003: 71).

Contudo, não podemos deixar de ressaltar os determinantes conjunturais que a sociedade brasileira está vivenciando, em termos de acumulação capitalista, desde meados dos anos 90 do século 20. Este novo padrão de acumulação dá origem a uma série de reorganizações no âmbito da provisão de políticas públicas em nível mundial, e igualmente dissemina ideologias, modos de viver e pensar que questionam significativamente os fundamentos da Modernidade - autonomia, universalidade e projeto histórico.

A emergência deste padrão de acumulação remete à crise dos anos 70 do século 20 , momento em que o capitalismo em nível mundial vivencia mais uma de suas crises cíclicas. A necessidade de o capital manter seus níveis de acumulação permite que um conjunto de propostas, que se convencionou chamar de neoliberalismo, precipite. Os rebatimentos da necessidade de o capital restaurar seus níveis de acumulação incidiram diretamente nas conquistas das classes trabalhadoras no âmbito dos direitos sociais. Um ponto crucial desta perda é a retração do Estado no que tange à provisão das políticas sociais e privatização destas.

Na direção da retração do Estado na provisão de políticas públicas estatais, e sob a bandeira de não pertencer ao segundo setor, o mercado, o chamado Terceiro Setor ${ }^{11}$ emerge

8,80) à precarização do emprego. Aqui, aliás, reside um dos aspectos mais expressivos da ofensiva do capital contra o trabalho: a retórica do "pleno emprego" dos "anos dourados" foi substituída, no discurso dos defensores do capital, pela defesa das formas precárias de emprego (sem quaisquer garantias sociais) e do emprego em tempo parcial (também frequentemente sem garantias), que obriga o trabalhador a buscar seu sustento, simultaneamente, em várias ocupações." (NETTO \& BRAZ, 2006: 218)

${ }^{11} \mathrm{O}$ Terceiro Setor, que abarca as organizações da sociedade civil, é fertilizado pelas premissas da sociedade da escassez bem como da crise fiscal, de forma irreflexiva (MONTAÑO, 2002). No bojo da crise do Estado, o 
em meio à satanização do Estado, ocorrida em um primeiro momento, principalmente, com as campanhas de Collor de Mello para a presidência, no final dos anos 80, nas quais os funcionários públicos eram representados como marajás ${ }^{12}$.

É diante desta trajetória histórica e desta conjuntura que vêm ocorrendo um processo de perda perversa dos direitos sociais e das conquistas das classes trabalhadoras que nos imputamos a necessidade de estimular a disseminação do PNDH-3 e suas possibilidades emancipatórias e de construção da autonomia às classes subalternizadas, por meio da potencialização da consciência crítica e de ações políticas na direção da democracia ampliada.

No sentido gramsciano, como socialização da política, ou seja, "do protagonismo político de amplas e crescentes organizações tanto dos trabalhadores quanto do capital no cenário de aprofundamento da democracia no capitalismo desenvolvido" (DURIGUETTO, 2007: 53, 54), configurando o cenário para a luta pela efetivação dos Direitos Humanos.

\section{Considerações Finais}

As atividades artístico-culturais parecem ter potencialidade de trabalhar as ações educativas e políticas em diferentes níveis visando o que Gramsci aponta como a formação de uma consciência crítica. Estes processos dependem das possibilidades de cada contexto histórico: dependendo das circunstâncias de cada momento, têm a possibilidade de avançar ou não nas suas propostas progressistas.

No âmbito dos Direitos Humanos, temos que levar em conta igualmente o papel da mídia na atualidade. $\mathrm{O}$ acesso às informações pela mídia de massa e a constante massificação da mercadologização das relações interpessoais e sociais, na direção da atomização do indivíduo implica na ampliação da disseminação da ideologia do consumo e do individualismo frente às questões coletivas. Não por acaso têm crescido nos movimentos sociais e na sociedade civil organizada mobilizações em torno do reconhecimento e da defesa do já denominado direito humano à comunicação. Tal perspectiva questiona a concentração de cerca de $90 \%$ dos meios de comunicação nas mãos de grupos de apenas onze famílias no

\footnotetext{
Terceiro Setor encontra ressonância igualmente na ideologia de incapacidade da burocracia estatal em solucionar as questões de cunho social.

12 Recorde-se as propagandas da campanha de Collor de Melo, nas quais os funcionários públicos eram retratados ou como marajás, ou como "fantasmas" por meio da emblemática figura do paletó na cadeira vazia. Nesta lógica, o Estado era representado como um paquiderme inchado e sem eficiência, indicando a ideologia da necessidade da privatização para impulsionar o crescimento e a eficiência dos serviços.
} 
Brasil. Afirma, ainda, que o ar, por onde passam ondas sonoras, imagens, informações eletrônicas etc. é um bem público, o que implica em democratizar o processo como se efetiva a produção e a transmissão da comunicação com multidões nos diversos países.

Neste sentido, o projeto de extensão em questão surge da proposta de pensar um instrumento que visasse a potencializar essa consciência crítica e a educação em direitos humanos, bem como objetivasse o estímulo à organização de ações políticas na direção da luta pela efetivação dos direitos no âmbito das políticas sociais públicas estatais, e que tivesse as questões de cunho pedagógico-cultural como eixo central de reflexão, tendo como ponto de partida os determinantes econômicos, os quais fundam a vida em sociedade.

É desta forma que as práticas extensionistas podem contribuir para a reformulação de valores e concepções reproduzidas em sociedade, como espaço de construção do conhecimento voltado à emancipação e autonomia dos sujeitos sociais envolvidos no processo.

\section{Referências Bibliográficas}

BARROCO, M. L. S. A inscrição da ética e dos direitos humanos no projeto ético-político do serviço social. Serviço Social \& Sociedade, São Paulo, ano 25, n79, 2005.

CFESS. Conselho Federal de Serviço Social. Código de Ética Profissional do Assistente Social, 1993.

DURIGUETTO, Maria Lúcia. Sociedade civil e democracia: um debate necessário. São Paulo: Cortez, 2007.

GRAMSCI, Antonio. Quaderni del Carcere. Edizione critica dell'Istituto Gramsci. Prima Edizione. Torino: Einaudi Editore, 1975.

GRUPPI, Luciano. O conceito de hegemonia em Gramsci. Rio de Janeiro: Graal, 1978.

NETTO, José Paulo \& BRAZ, Marcelo. Economia Política: uma introdução crítica. Coleção: Biblioteca Básica de Serviço Social. Volume 1. São Paulo: Cortez, 2006.

NETTO, José Paulo. Ditadura e Serviço Social: uma análise do Serviço Social no Brasil pós-64. São Paulo: Cortez, 1991.

"A conjuntura brasileira: o Serviço Social posto à prova". In: Serviço Social \& Sociedade. São Paulo: Cortez, nº 79, Especial 2004. 